\title{
Ground Sound
}

Colette Urban

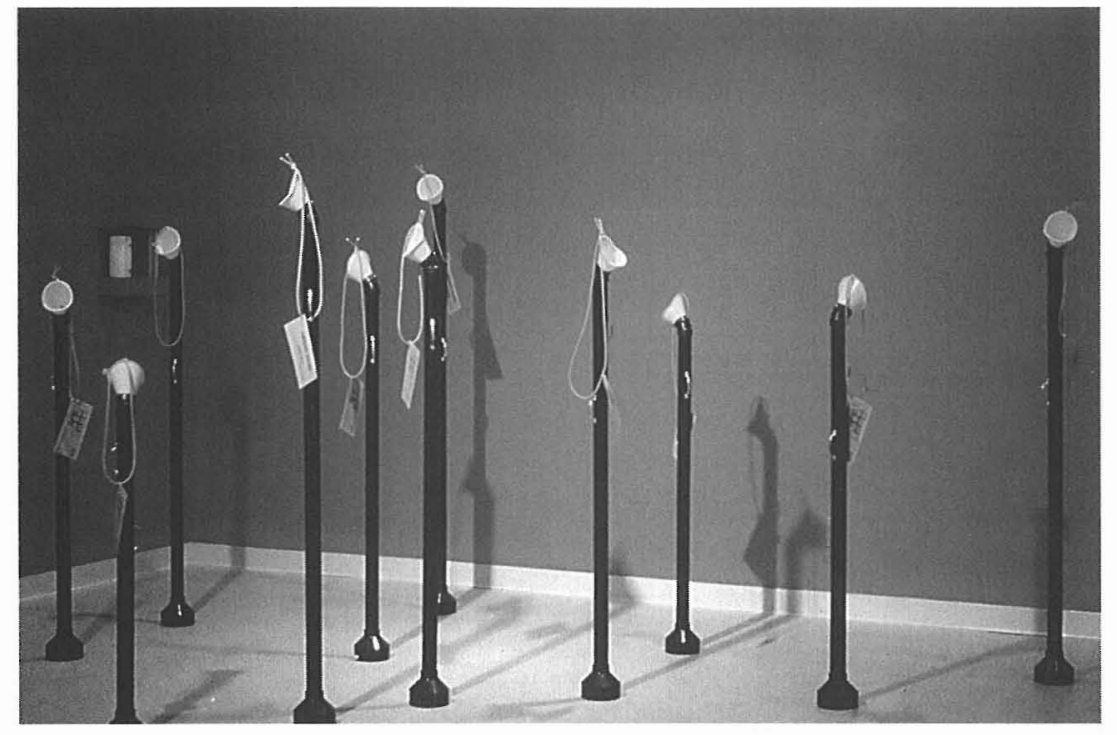




\section{Ground Sound · 61}

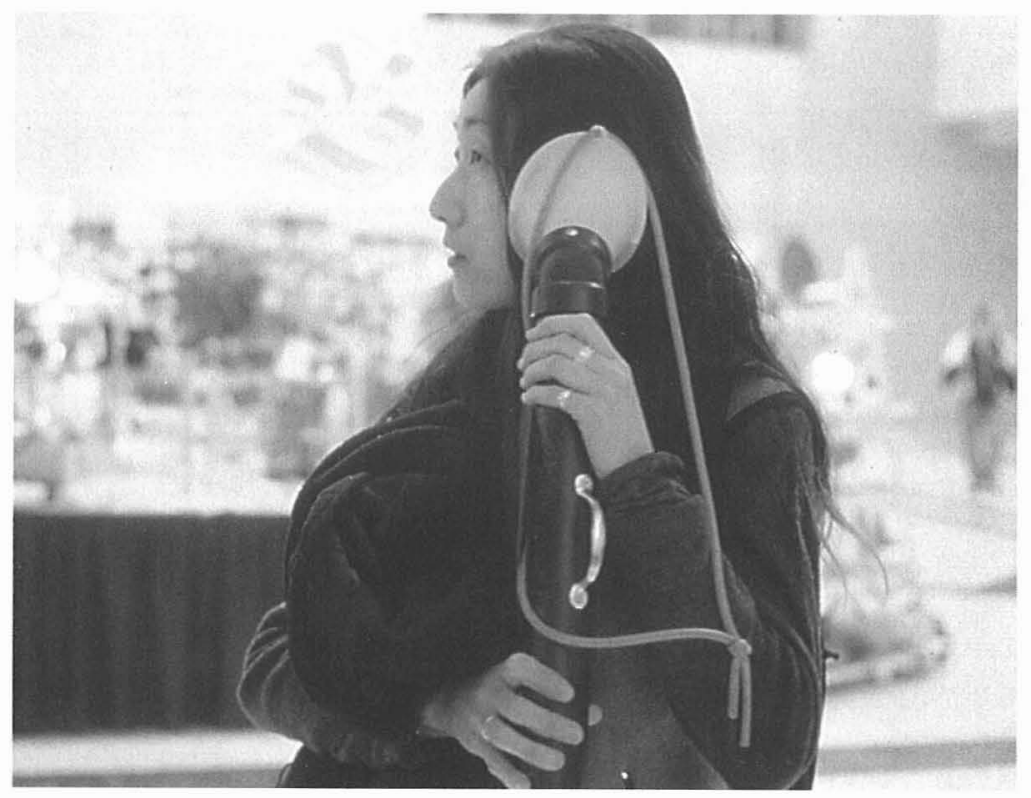

Ground Sound is an interactive performance where participants are invited to take an ear-horn for a walk. The horns function by delivering, to the ear, the amplified sound found at one's feet. This unfamiliar audio environment provides the participant with a new and complex acoustical experience of a familiar activity, walking in the city. The introduction of the new experiential dimension of the work is further complicated by the "look" of the construction-appendage which hovers between legitimate scientific apparatus and humorous child's toy. The ear-horns are constructed from plastic hardware fittings that vary in height to accommodate the performer. Ground Sound was installed at Michael Gibson Gallery in 1998 and the Art Gallery of Windsor in 1999. 